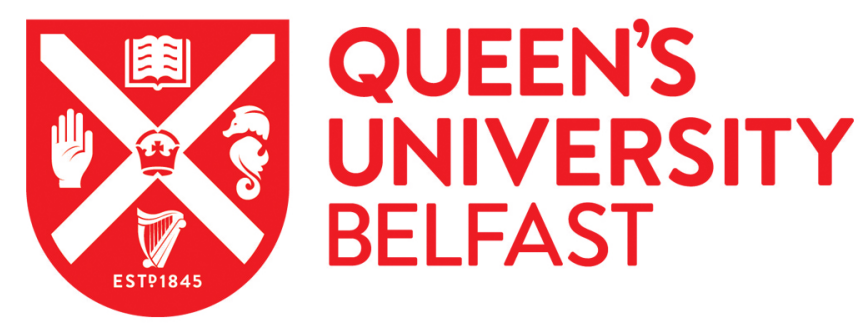

\title{
The importance of critical judgment in uncertain disciplines: $A$ comparative case study of undergraduate fine art visual practice
}

Belluigi, D. Z. (2018). The importance of critical judgment in uncertain disciplines: A comparative case study of undergraduate fine art visual practice. Arts \& Humanities in Higher Education, 17(3), 305-322.

https://doi.org/10.1177/1474022217712641

Published in:

Arts \& Humanities in Higher Education

Document Version:

Peer reviewed version

Queen's University Belfast - Research Portal:

Link to publication record in Queen's University Belfast Research Portal

Publisher rights

(c) 2017 The Author. This work is made available online in accordance with the publisher's policies. Please refer to any applicable terms of use of the publisher.

\section{General rights}

Copyright for the publications made accessible via the Queen's University Belfast Research Portal is retained by the author(s) and / or other copyright owners and it is a condition of accessing these publications that users recognise and abide by the legal requirements associated with these rights.

Take down policy

The Research Portal is Queen's institutional repository that provides access to Queen's research output. Every effort has been made to ensure that content in the Research Portal does not infringe any person's rights, or applicable UK laws. If you discover content in the Research Portal that you believe breaches copyright or violates any law, please contact openaccess@qub.ac.uk. 


\title{
The importance of critical judgment in uncertain disciplines: a comparative case study of undergraduate fine art visual practice
}

\author{
Abstract \\ Criticality is an important means to negotiate uncertainty, which has become a characteristic of \\ teaching and learning conditions in postmodern times. This paper draws from an empirical \\ comparative case study conducted in the uncertain discipline of fine art visual practice, where \\ critical judgement and metacognition are important for professional contemporary art practice. \\ Charting the curricula intended by staff and the culture experienced by students, the paper \\ considers the relation between the espoused theory of criticality in two art schools and their theory- \\ in-use within assessment structures and cultures. Emphasis is placed on the significance of such \\ approaches to criticality for the student experience and their learning engagement. Emerging \\ discourses of 'subjectivity' and a lack of development of student meta-cognition indicated that, at an \\ undergraduate level of study, the curricula of these cases are unwittingly underpreparing their \\ graduates for operating with agential criticality as they enter the uncertain context of contemporary \\ art.
}

\section{Keywords}

metacognition, creativity, agency, criticality, uncertainty, assessment

\section{An uncertain discipline}

The 'will to criticality' in this age of supercomplexity (Barnett, 2000) can be enabled in higher education curricula through conditions which are underpinned by the principles of solidarity, hospitality, safety, and re-distribution of power (Mann, 2001). However, traces of the desire for stasis and security - the moral, political and epistemic concerns of early modern philosophical thought (McCall, 2016) - continue to pervade higher education. Some have even questioned whether formal education actually values self-actualization (Danvers, 2003; Friere, 1972; Habermas, 1972) over and above predetermined outcomes and coercive assessment practices, where often political interests are served at the expense of ethical concerns (Burnard, 2006, 2007; Craft, 2006).

Critical judgement is particularly importance in disciplines that themselves are uncertain. More so now than ever, certain disciplines are beset by an onto-epistemological paradox of questioning that goes to the core of not just what to teach, in terms of the canon in the face of post-colonial or feminist critiques for instance, but to the very nature of their discipline, such as fine art visual practice (Harwood, 2007) which radically engages with philosophical shifts in the nature of art and the postmodern condition (Schiralli, 2002). Its many diverse influences include various adult learning traditions (Boud, 1989) and traditions of creativity (Belluigi, 2010; Cowdroy and de Graaff, 2005; 2007). Transformative learning is considered central in art education, with connections between ontological, epistemological and performative dimensions (Danvers, 2003; Martin, 2002). Contemporary curricula in the main espouse adopting approaches which either question structures that disempower the student, from the critical tradition of adult education, and/or enable the inclusion and positionality of discourse and the personal narratives of students, from postmodern notions of adult education (Usher and Johnston, 1997). 
This is because the ideal construction of the knower in this domain is the artist as reflexivity practitioner (Belluigi, 2016) akin to the practicing intellectual or the revolutionary who uses his/her self-knowledge to cultivate insecurity.

The artist's peculiar responsibility lies in the fact that he is always at war with his society and its fixation on keeping up the appearance of a stable, unchanging social space (McCall, 2016: 6).

Such engagement with self-knowledge, the self-criticality it engenders, and artistic practice itself, are acknowledged as difficult (Baldwin, 1962). Echoing the complexity of intersections and intermingling of Winnicott's transitional space, art can

be thought of as an indeterminate condition, a threshold between conscious thought and unconscious feeling, an opening onto a liminal space where rationality (theory) and irrationality (experience, emotion, art) mix in the individual creative act (practice)

(Dallow, 2003: 49).

As such, art education research acknowledges that arising from such boundary-pushing is the unknown and unexpected, both in terms of learning and of teaching (Kindler, 2007; Pistolesi, 2001; Schiralli, 2002), as very little can or should be predetermined. With this comes a profound affective dimension to learning, as students have to learn to cope with instability and uncertainly in the processes of artmaking and learning (Danvers, 2003; Edström, 2008). Negotiation of such affective complexity requires responsiveness and receptiveness of both staff and students in art education (Freeman, 2006).

\section{The importance of critical judgment}

As the activity of artmaking is at the centre of the knowledge generated or employed in this domain, practice can be seen to both directly shape the contemporary field and supplement theory (Wild, 1998: 51). The artist, much like the theoretician, is enabled to pose questions not only about but through the work. Such constructions of artmaking make allowance for creative agency while necessitating a developed capacity for criticality.

A critical, theoretical disposition helps frame and limit the answers found in research by making them contingent - specific to the historical moment and the particular context from which they emerge; in effect, situated knowledge and timeliness replace objectivity and timelessness (Blauvelt, 1998: 75).

Strong arguments have been made about the importance of having moral or ethical frameworks from which to both develop and evaluate creativity (Craft, 2006). The ability to not simply handle but anticipate and work with uncertainty, creative tension and emotional discomfort (Runco, 1994), can be developed in artistic practice by creating opportunities for reflective and critical enquiry to encourage "epistemological and emotional problematisations of individual and collective emotions, histories, and sense of self" to encourage "critical respect for difference" (Boler, 1999: 176). In addition, linking creativity with processes of reflexivity or evaluation is towards critical pedagogic ends of encouraging students to question the political or other ends which their creativity serves (Craft, 2006: 347). 
Despite such recognition and concern evident in published art education research, empirical studies of pedagogy have found that the association between creativity and critical thinking may be from strategically adopted quality assurance or educational development discourses (Belluigi, 2009). They may remain at the level of the espoused, rather than substantively at the level of the practiced. For this to underpin that which is practiced, requires emotional self-knowledge and assertion by the agents involved, which may then be enabled or constrained by the structures and cultures in which they are situated. In practical curricular terms, tasks and methods which involve and support students in actively entering uncertain terrain to question or create problems from the set assignment topic or 'brief' (Freeman, 2006; Reid and Solomonides, 2007) rather than slavishly finding solutions, are most favourable. At a more fundamental level, this may also necessitate that more autonomous and meta-learning learning occurs (Freeman, 2006)

This article stems from a research project which looked at a domain where creativity, criticality and agency are of utmost concern (Belluigi, 2015). Towards this, empirical data was generated and collected from two fine art institutions which acted as comparative cases for mapping and contrasting interpretative approaches evidenced at assessment practices, structured by curricula, and at times supported and others complicated by the agents interviewed. The article highlights the insights which emerged in terms of the development of students' critical capacity, indicating that student authorship may be an important consideration within assessment in similarly uncertain disciplines.

\section{Methodology}

The larger project, from which this article emerged, aimed to address the dearth of sustained research on the relationship between the problem of authorship and approaches to interpretation in the assessment of the creative arts in HE, where it is recognised that the student-artists' intentionality is not a focus of any of the dominant studio teaching traditions (Cowdroy and de Graaff 2005). I considered two art schools influenced by similar traditions of art education: AS1 in the UK and AS2 in a post-colonial context ${ }^{1}$. They were purposively selected for how they differed in terms of their publically espoused approach to intentionality in assessment, i.e. whether interpretation at assessment is inclusive of authorial knowledge. In their curriculum documents and communication with students, AS1 espoused an intentionalist approach which was explicitly reflected in the structural inclusion of back-up material for the summative assessments where assessment criteria encompassed the person, the artmaking and learning process, and the product submitted for assessment. In contrast, AS2 espoused an anti-intentionalist summative approach, with an exclusive focus on the product displayed through assessment-by-exhibition, which is traditional in this domain. To determine the espoused approach, I analysed the schools' curricula documents as these act as artefacts of institutional espoused theories and the discourses they project. I conducted a content analysis of terms that dominated, in addition to criteria and discourses which resonated with the subject at hand, and how they positioned the student-artist and related authorial knowledge. To ensure the soundness of my interpretations of each schools' espoused approach, I presented my interpretations to the participating staff, who I invited to act as

\footnotetext{
${ }^{1}$ Not relevant for the focus of this paper, Belluigi (2016) touches on those aspects of the curricula of these schools which were impacted by their developing/ed contexts.
} 
both informants and critical readers to that 'report-and-respond' data generation process (Stronach and MacLure, 1997).

All the staff and students involved in the final year of undergraduate studies were invited to participate. Nine of the 16 staff and 10 of the 65 students at AS1 actively participated; all 5 staff and 16 students at AS2 participated. In addition to the analysis of curriculum documents described above, data from staff participants was generated from interviews, questionnaires, emails and observations of formative and summative assessment events. Visual narrative focus group interviews (Belluigi and Meistre, 2012) and emails were utilised to generate data from student participants, in addition to observations of their formative assessment interactions with peers and staff. Interactions with participants were staggered through ever-deepening engagement with my analyses. These served the purposes of disseminating my interpretations to participants, and enabling them to challenge or further extend these, adding nuance and complexity.

To tease out such complexities from the data, a framework to map interpretative approaches was constructed, which analysed the role played by the positioning of the artist, artwork and viewer to determine the relationship of authorship to textuality and readership (Belluigi, in press). To consider the significance for student learning, a schema for the conditions for creativity in fine art studio practice was utilised (Belluigi, 2013).

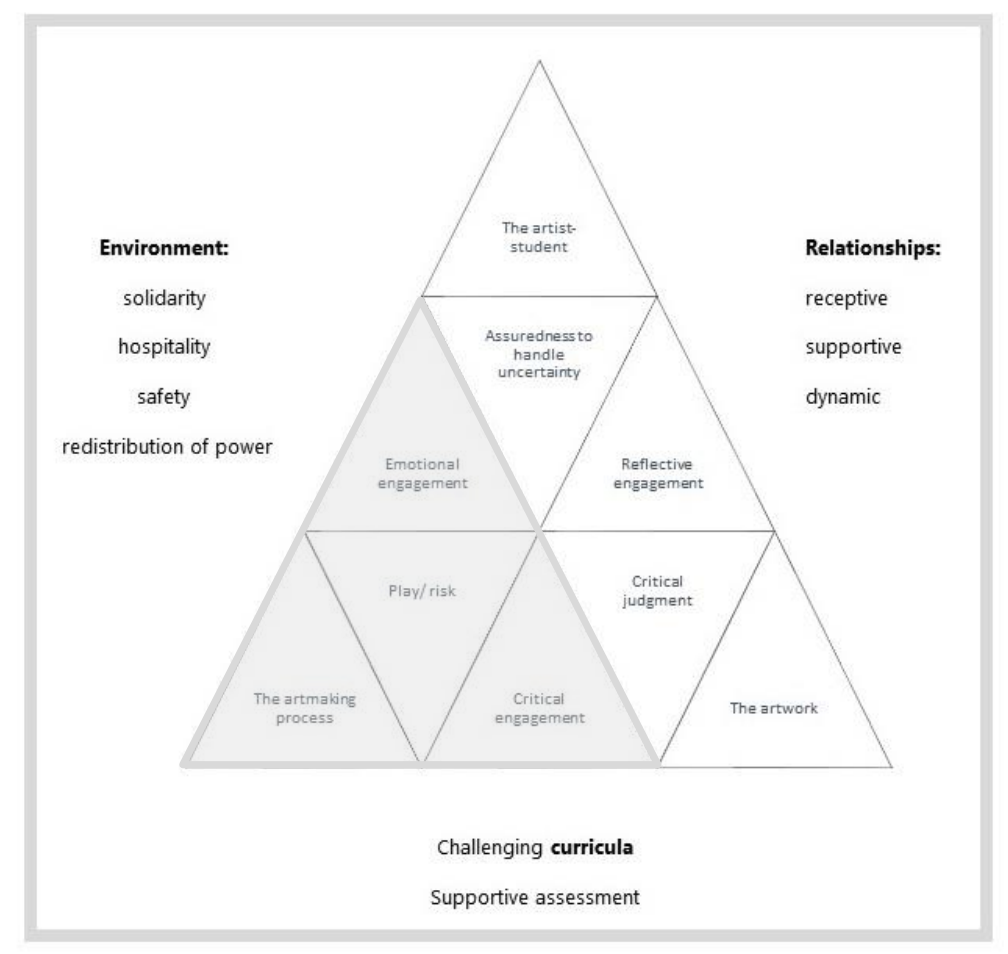

Figure 1: A schema for the conditions for creativity in fine art practice education from Belluigi (2013)

For the purposes of this article, I have focused on the lower right apex of the triad of the schema (indicated by the shaded areas in Figure 1) as these relate to criticality: critical judgement, engagement with the artwork as the 'product' of the learning process, and reflective engagement. These demarcations were helpful for analytical purposes, however fluidity with other related components of the triad, and the larger environment within which it is situated, occurred. 
The intensive process of triangulation of methods and member-checking enabled me to comprehend both that which was espoused or intended by the school, that which was practiced in the assessment processes, and that which students experienced. These varying perspectives are reflected in the structure of the next section of this article, which considers firstly the relationships between what was espoused and what was practiced by each school in terms of criticality, before considering the significance of that for student learning, experiences and meta-cognition.

\section{Approaches to criticality in the cases studied}

Both schools explicitly aimed to develop their students in the model of the contemporary artist as reflexive practitioner where reciprocal exploration of the political and historical content with the form, context and reception of the artwork is expected (Dallow, 2003). The staff I interviewed presumed that such critical negotiation with the content of their courses placed them within critical or postmodern traditions of adult art education, however whether this was the theory-in-use or translated to pedagogical practices, required further investigation.

The 'knowledge capability' approach of problem-based learning (Bowden, 2004) is considered at a lower level of learning than the divergent and exploratory problematizing necessary for the development of a contemporary artist (Corner, 2005). In the institutions studied, this was enabled through the contextualising curricula which engaged students in problematizing the discourses they operated within. Indicated from the data generated on the student experiences at both institutions, opportunities for transformative learning were enabled through these challenging curricula. The possibilities of perspectivism, where critical evaluation allowed space to exhibit diversity, difference and pluralism (Danvers, 2003), were created in the peer interaction at formative assessments at AS1 and to a lesser extent in the studio at AS2. However, such multiple perspectives were not exercised as horizontal when interpreting the work, with students and their self-assessments excluded from the summative assessment structure in both schools.

The majority of students in both schools had characteristics of the 'squeezed middle'(Jackson, 2013), coming from a lack of critical cultural capital to fundamentally question and challenge themselves. However they were encouraged and in different ways enabled to adopt critical stances to their own artmaking, with a strong expectation that received opinions, ideological positions and commonsense assumptions from the world outside the art school be challenged and fundamentally questioned to create an appreciation of the "inherent revisibility of knowledge" (Danvers, 2003: 51). Most dominant in the AS2 culture was the challenging of conservative and outdated understandings of art prevalent in South African society, although the dominance of western contemporary aesthetics seemed unchallenged. A critical accent was encouraged when it came to the research content, where that which was "sinister"; "challenging"; "ambiguous" (adjectives more prevalent in staff feedback) was valued over an appreciative or representative approach ("too pretty"; "didactic"; "depictive"; "illustrative"; "tame"). The critical emphasis was on opening the work to a diversity or nuance of readings. One of the more successful students, Chelsea ${ }^{2}$ experienced conflict with this culture when negotiating her own desire for an appreciative enquiry of her subject matter, in the face of such powerful encouragement of a more 'critical' interpretation of her subject.

\footnotetext{
2 Participants were invited to choose pseudonyms, with the guidance that the names they chose should retain demographic traces. Their responses reproduced in this article were selected as most representative of particular experiences or discourses.
} 
I wanted it to be sort of hopeful and they don't like that. It's just such a strange tension between two worlds.

While aspects of criticality were evident at AS1, there was far more allowance for lighter aspects, such as curiosity and playfulness in students' negotiation of subject matter or research subject.

Self-directed learning, independence and responsibility were linked with meta-cognition at AS1. There was an attempt to establish the conditions for the making and reading of art, which if effective would lead to "critical self-awareness" (curriculum document). However, students' self-assessment of their work or their learning development was not included within the assessment process. While opportunities were created, formally and informally, for verbal formative peer assessment (in seminars, tutorials and in the studio), and reflections within the research log and back up material, self-assessment was not a discernible criteria or consideration within the assessments I observed. At AS2, meta-cognition had been strategically included as an outcome within the dormant curriculum documentation produced for quality assurance purposes. In communication with students, it was not explicitly conveyed as fundamental to their learning. Most noticeable, when students would talk briefly about their research projects and processes at the commencement of each formative assessment event, such self-representation included little self-reflection, and the questions posed by assessors were not formulated to explicitly encourage such reflection. As there were negligible written components within the assessment structure, opportunities for deep reflective engagement with their artworks or their development were lacking.

Emerging from both schools were referential frameworks for summative assessment which undermined their espoused critical orientations, as neither situated the artist-student within their interpretative approaches. Whilst artwork in the contemporary artworld may operate without the artist having the agency to determine its meaning or significance for the reader, most of the staff contended that, for their own critical evaluation as developing artists, the students' intentionality was important. This distinction was also made in the Intentionality Fallacy, where Wimsatt and Beardsley (1946) differentiate between the role played by interpretations for art criticism, and those made for the composition of artworks, and by implication, artistic development. However, complications arose within summative assessment, which sits in the threshold between the evaluation of the artmaking of novices and gatekeeping for the professional community of practice. Despite the practice-based staff members' recognition of the role it played in their learning, I observed that students' actual intentionality was not given substantive consideration for summative assessments in either school. The effect of this mis-alignment on formative assessments, where staff were best placed to develop meta-cognitive skills, was evident when staff acted as representatives of assessment processes rather than mediating those purposes as members of a professional community of practice which requires its members to be actively self-critical.

Thus whilst the schools may have espoused differing approaches to interpretation and the inclusion of intentionality, the study found that neither included actual intentionality in their referential frameworks for assessments. The artist-student's actual intended meaning of his/her work and how $\mathrm{s} /$ he might consciously negotiate the audience's engagement with his/her work, was not an assessment criteria. Rather, when intentionality emerged, it was 'hypothetical' or 'valuemaximising', with authorial intention constructed through the interpreter's projections. The backwash of such approaches, which privileged textuality and readership, on the formative 
interactions with students resulted in a lack of value for students' reflective engagement with the artwork they had created and how it corresponded with its reception, which in turn weakened the development of their critical judgment, as I discuss within this article. Thus whilst both schools espoused critical and postmodernist approaches to the content of their programmes, because of their summative interpretative approaches, neither could be positioned sitting strongly within critical nor postmodernist traditions of adult education.

\section{Significance for student learning}

But one thing that I never quite figured out, is when someone says 'yes' to a work, when they think it's great and it's going really well. What I still haven't figured out is - Why?

In an attempt to answer the question above, Tessa (AS2) echoed the discourse utilised by so many of her peers - constructing the evaluation of art as "all so subjective". Although a high achieving student, she defaulted to this everyday conception of interpretation in her understanding of the complexity of the assessment process. Many students revealed a similar sense of bafflement with or frustration around the lack of comprehension and insider knowledge of the assessment process. In their narratives many of them oscillated between questioning the validity of their assessors' judgements and relinquishing agency for the readings in the face of the supposed relativity of the "subjectivity" of aesthetic criticism. A sense of futility of submitting themselves to such pedagogic processes, compared to larger questions around the reception of the work, emerged.

Art marking is subjective, I really do think it is. But if you want to be an artist, you go to Art School, and get marks. And, ja I think that's why, you don't really know. You're trying to say something with an artwork and - whether or not the lecturers think that it works or not - chances are you actually don't really know because it may not be out in the public or, I'm not sure, it's very hard (Lenore, AS2).

A lack of in-depth comprehension of assessment processes and the referential frameworks was evident in student responses at both schools. This indicated that, despite the attempts at AS1 to establish shared understandings by making aspects of the judgment process explicit and transparent through criterion-referenced assessment, the complexity of assessment in this domain rendered such interpretation opaque to students, without additional participatory assessment in those judgement processes to engage with the habitus. Instead, what emerged as prevalent in both schools was the 'subjective discourse' alluded to above. Students articulated believing art was assessed subjectively, rather than recognizing that frameworks existed which may be relative or localized and that "subjectivity in aesthetic judgement lies not with individual idiosyncrasy but with selection of tradition(s) within which judgements are contextualised" (Bolton, 2006:72).

A slightly different subjective discourse emerged in my observations of and discussions with staff in both schools too, who seemingly adopted a construction of subjectivity and objectivity as dichotomised. Such tensions have been noted within this domain, where despite nuanced notions of subjectivity within contemporary notions of interpretation, the tendency was to position assessors as objective experts, particularly those in the role of moderating academic assessment (Belluigi, 2015).

In the following sections I consider in some depth the significance of the schools' assessment structures and cultures on the ways in which students experienced engaging critically and 
reflectively during their studies. The discussion is structured by aspects of the creativity triad critical and reflective engagement, and critical judgement - discussed in the methodology section.

\section{Student experience: AS1}

Aligned with the school's espoused theories, critical engagement was communicated in the AS1 course documents as an important criterion for assessment. For Tammy, the shift from immersion in play during the artmaking process to the critical distance of the assessment event "where you see your work from the distance that everyone else is seeing it", was "a profound experience". She found such formative assessments collegial, where all had "a common goal" and were supportive. Tammy characterised her own reflective process as "so erratic and haphazardly all over the place that it kind of like happens in sort of patches everywhere... a serious monkey-brain". The collaborative critical engagement in and readership of her work was comparatively invigorating. The majority of students, however, described their strongest sense of engagement and 'flow' during the artmaking process itself, as a dialogue with the textuality of the work.

Whilst opportunities for "critical analysis, reflection, presentation and reception" (course documentation) were created in the various formative assessment contexts, research log and portfolio, it was not made explicit to students that these were intended as opportunities for metareflection to develop reflexivity in their practice over time. As the accent was on self-directed learning, the quality of such engagement was left to student devices. Dave, for instance, found that formative feedback had little influence on his process, continuing after such assessments "as I wished". This may have been because, as with a number of students at the school, he felt much of the feedback was irrelevant or conflicted with his desires, which he had conviction should guid him. Whilst this had resulted in him "developing my own opinions rather than be led", he felt that the nature of the feedback had left his own critical engagement unsupported. As his self-assessments were not substantiated, he felt that the degree of uncertainty stunted his capacity to discern their validity, "I do wonder if I can really trust my judgment or if I [am] delusional or biased about judgments". Echoing a number of students' sentiments, he felt that the feedback, whether verbal or through indicative numerical grades, did not help him develop a sense of the standard of his work and skills.

Very few students offered an alternative explanation for judgments from the dominant subjectivity discourse. One was Else, who revealed an awareness that what was constructed by staff as 'successful' was contextualised within specific frameworks which the school had adopted. She used scare quotes when she wrote "'good' work will be praised" in the text under her visual narrative, further asserting that such constructions were provisionally dependant on the judgements and approval of the assessors.

Depending on dispositions and previously developed skills of reflection, varied levels of reflective engagement emerged in the students' stories. For instance, Else was able to identity aspects of her artmaking process and affective aspects of her learning which required attention. Joe's ability to selfassess was a result of his resistance to accepting the dominant discourses. Paradoxically, those who experienced conflict, particularly related to internal or external motivation, developed the strongest reflective skills. Characterised by actual intentionalism, these were noticeably misaligned with the assessment criteria and interpretative approaches of the school. 
The majority of student participants noted that aspects of formative assessment, particularly critical engagement, created tension with their emotional engagement with play and the agency of the artwork as a text during the process of artmaking. For Fran, the sense of connectedness with process and textuality, when she was able to focus "just on the work" in a single-minded way, was altered once critical engagement from the feedback of others was introduced. She actively sought to return to that sense of flow and dialogue with the work (represented as "finding that chair" in the second and third block of Figure 2). She characterised this as a conflicting, halting process requiring perseverance on her part.
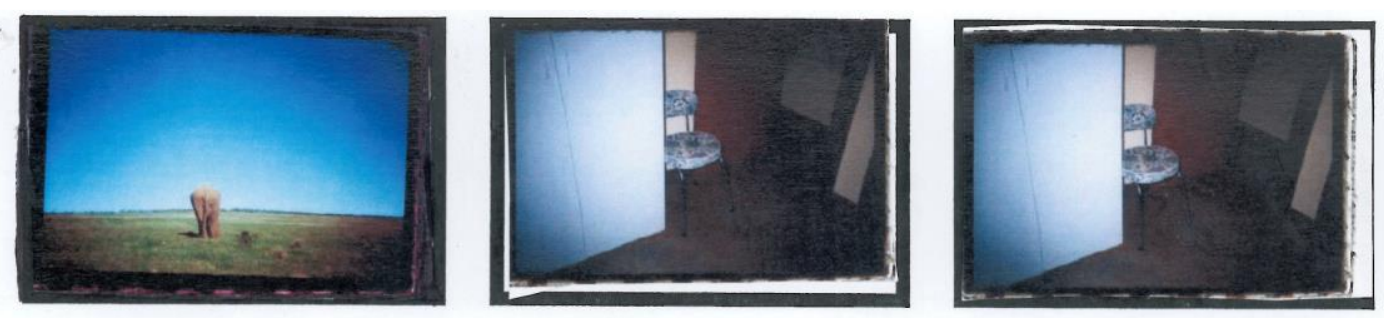

Figure 2: The difficultly of engaging emotionally after disruption from the critical gaze

Similarly, Dave spoke about how critical engagement changed the nature of his previously unfettered relationship with the textuality of his work. As with many students at both schools, he expressed nostalgia for a time when he made art outside of academia, without the critical interpretative gaze of readers.

Such melancholia and schism was most noticeable when it came to nominal authenticity (Dutton 2003), which informed students' reflective engagement of their own artworks. Fiona, for instance, described the critical judgment she had developed in reference to her intentionality as "a more grounded sense" of how to evaluate staff feedback against her own strategy for the reception of her work and how it operated in the world. Unlike staff approaches, such authenticity underpinned students' conceptions of the development of their authorship. Due to the anti-intentionalist structures and culture of assessment described in the previous section of this article, such reflective engagement was unsupported by most formative interactions, and was most often characterised by conflict between their own desire to realise their actual intentionality and the influence of strategic thinking for assessments. Experiences of alienation as a result of this conflict led some students to question those in positions of authority within the school.

Who are these people to assess my work, and if it's a case of like extensive knowledge and years of experience and stuff like that?

One student described "feeling a real antagonism" about the effects of such institutional authority on her artistic autonomy. Perhaps because this uncertainty occurred at undergraduate level, such thinking resulted in dis-engagement with the textuality of the artworks, most often during the processes of making and their reflection on the product of their labour, for the majority of the participating students. For instance, one student described this alienation as having unwanted effect of questioning "'Do I actually like art?' and I hated that".

\section{Student experience: AS2}

Characterised by the traditional master-apprentice model (Belluigi, 2016), critical engagement was strongly directed and managed by the supervisors and assessors at AS2, unlike AS1 where critical 
engagement was posited as an aspect of self-directed learning. In addition, the tone of formative assessment feedback often lacked positive affirmation and did not make much of achievements or exemplars of good practice.

There's never really a good strong enough voice of reason I find, that sort of gives you that feeling like, 'Ok, I'm actually achieving'. They never actually just sit you down and say 'you know what, you're actually doing great', it's always 'something needs to be fixed', and 'something isn't right', it's never just. I don't know why they can't just do that... Why can't you just tell me l'm doing alright you know? (Lenore)

Most students of this school expressed paralysing anxiety at not having developed the critical judgment to determine a 'successful' or 'good' artwork. With this came a sense of disenchantment with formative feedback. One such student explained how only in her final year had she gained enough confidence to act on her frustrations about the lack of "value" of such feedback, but found that even asking for specific feedback had not been fruitful. Stanley spoke about having developed more surety about his own ability to respond to criticism by gauging "from whence it comes".

I think the way I respond to criticism and ideas has improved since I've been at $X$ [AS2] and allowed me to improve on myself and my work.

While he respected the assessors' feedback, explaining that "I take all my lecturers' words seriously, I know they've got the experience", he filtered their feedback by how he evaluated them as fellow artmakers, which he felt "levels" their reading as assessors "a little bit more".

A number of students voiced feeling uncertain about whether their critical engagement was aligned with the implicit criteria at the school. Jade's narrative (Figure 3) related directly to her lack of capacity to discern the criteria referenced by her assessors in their role as readers, and to understand what was rewarded within the school's habitus.
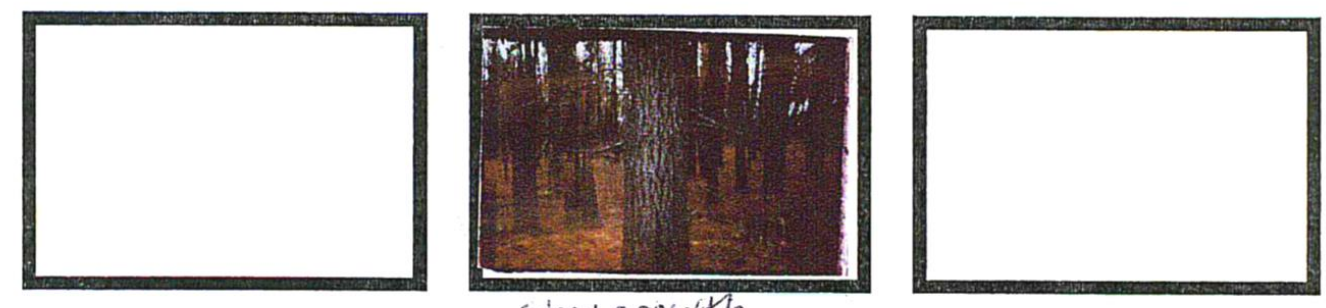

Your words:

slowgrowth.

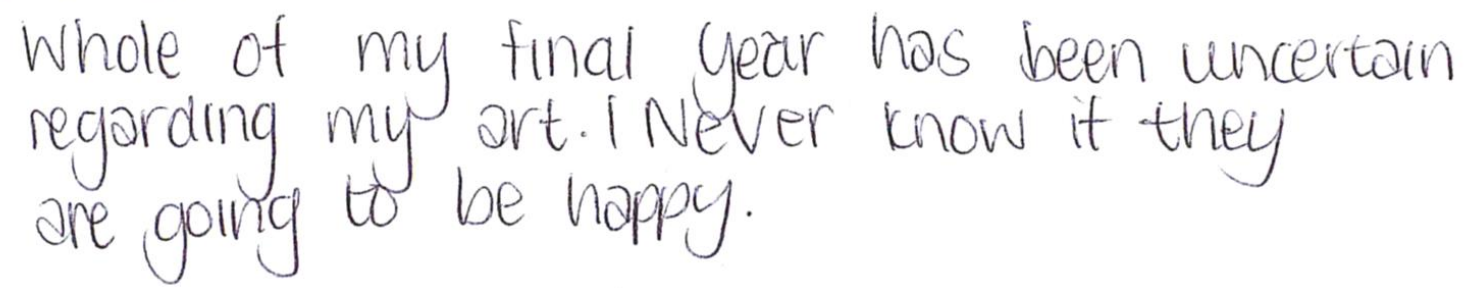

Figure 3: Jade's visualisation of her growth retarded by uncertainty within her critical engagement

She explained that the constant uncertainty "holds me back" in her development as she felt unable to proceed with any confidence. This was exacerbated in her final year, which had been entirely externally prescribed during formative assessment, rendering her unable to discern the purpose of 
the project and its role as a text. As such, she could not share the "end goal" which the assessors envisaged, and was exacerbated by how "I still, every day, I don't know what I'm doing".

Laura indicated that her assessment experiences during her fine art studies had taught her emotional resilience ("forced you to grow thicker skin") to accept that not all reader-responses would be favourable. She had come to accept critique as inevitable and subjective, rather than having developed capacity to evaluate the worth or relevance of such interpretations and perspectives.

You have to accept peoples' judgments and their criticisms and their advice, no matter how good or bad it is... I can accept it but I won't hold on to it for too long now.

Sindisiwe had experienced staff feedback as being helpful for self-knowledge despite her own experiences of alienation and her discomfort with the assessment event.

When I look at where I started and when I look at myself now, there's a lot of growth, and all that criticism at that point in time, it looked like it was so unnecessary and harsh, but actually it kind of, I don't know, it got me where I was now, I'd say.

As a way to comprehend her lack of shared understanding of the assessors' referential frameworks, Tessa spoke about how very different and uncertain fine art visual practice was compared to other studies. She focused on the artefact produced for assessment purposes: how the guidelines for essay writing in a standard Bachelor of Arts degree empower students to do well and understand "exactly" how the essay may be strengthened, as "there is a formula there" upon which feedback could be based. Her experiences of fine art were that the habitus was more complicated, and that there was an element of agency within the textuality of artwork that added uncertainty.

Meta-level or reflective engagement with the artworks was not an explicit concern within the curriculum structure and culture at AS2. In addition, the anti-intentionalist summative approach created conditions which did not validate individual supervisors' facilitation of such skills during the artmaking process. As with AS1, the aspects of reflective engagement that emerged from student stories related to skills of self-assessment; their meta-cognition; and the relation to these to intentionality and strategic approaches.

For instance, Lenore's independence and in turn development of her own skills of reflective engagement had been born from experiences of invalidation within relationships.
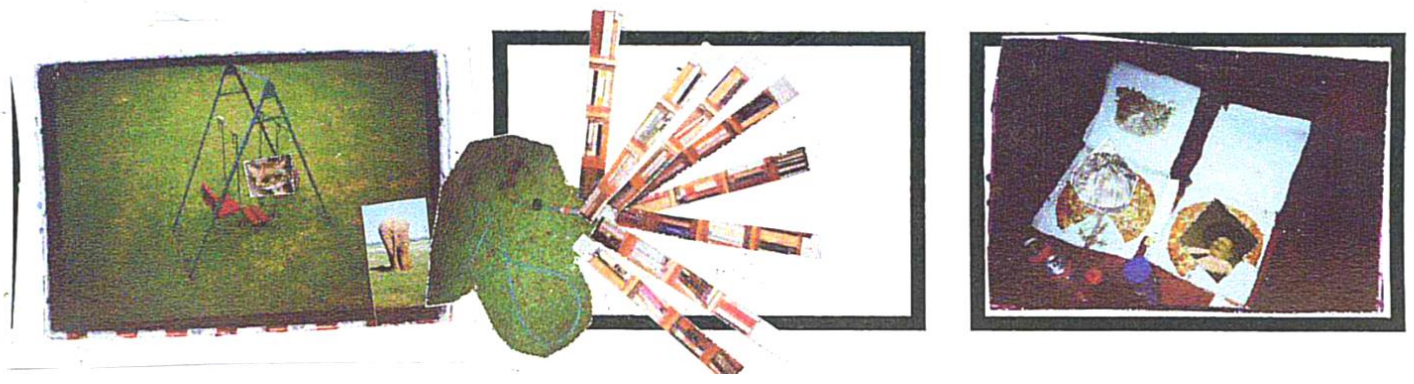

Figure 4: Lenore's visualisation of the development her self-assessment skills 
Expressed in Figure 4, in the first year of her studies she felt isolated as "the only cat on the swing". As a result she developed resistance ("the bums up" represented by the elephant's hind quarters) which freed her from an expectation of affirmation through staff-student relationships. This paradox of resentment (Govier, 2002) was echoed by a number of students. A sense of release from assessors' authority was visualised in the spliced bookshelf image, with strips fanned out from this act of resistance.

That's sort of what's resulted in, I don't know, a sort of pizza-like reflection of collaborating with yourself more than collaborating with what someone might potentially want you to [do].

The last image, of two pizzas overlaid with parts of a Dutch portrait painting, was constructed to create a sense of her learning being in dialogue with her own internal critical voice(s). As with students at AS1, such internal frameworks rarely aligned with the school's interpretative approach which was demonstrated within the summative panel assessment discussions I observed.

\section{Considerations of meta-cognition}

In both institutional cases, concerns about the development of students' meta-cognition of interpretation arose. However, the implications of this finding would seem to be vastly different, due to the contextual conceptualisations of the function of the undergraduate qualification (see Belluigi, 2016).

AS1's espoused intentionalist approach was confirmed as a dominant implicit theory-in-use within summative assessments. Staff purposefully complicated this approach, for the purposes of criticality, by incorporating anti-intentionalist readings of student work within some of the formative assessment events. However as actual intentionality was not referenced or legitimated as a selfassessment criterion in relation to such readings, meta-cognition in terms of student authorship was often underdeveloped. This finding proved not much of a concern for staff and students at this school at the time the study was conducted, as the undergraduate degree was conceptualised as the beginning of the artist's lifelong learning process of negotiating the complexities of authorship. Interviewed staff indicated that authorship operated in a considerably different manner in postgraduate courses. With recent changes to fee structures in UK higher education, the luxury of access to postgraduate study may be adversely affected, and so the reception of this finding in schools such as AS1 may shift in time.

The espoused anti-intentionalist interpretative approach at AS2 was confirmed as the theory-in-use within their summative assessments. Students at this school were similarly underdeveloped in terms of their reflective engagement as those at AS1, which was further weakened because of their dependence on their supervisors' readership. Mentorship which was mostly enacted through the responsibility supervisors took for guiding the students' processes towards resolution and success for the summative assessment. All participating students' reflective engagement with their artworks was underdeveloped, with the majority of students severely lacking confidence in this regard. This may have been from a backwash of the anti-intentionalist approach, where self-assessment of the works' reception against the students' intentionality as author, and meta-cognition of the students' oeuvre and development, did not factor in formative processes nor summative assessment discussions. A major concern about these students' ability to operate as reflexive authors of their 
own work emerged, particularly since the undergraduate degree in that context was conceptualised as an entrance to professional practice.

Frames of reference drawn on for assessment processes in higher education are underpinned by the interpretative approaches utilized, implicit and explicitly. These are situated within curriculum structures, and institutional and professional cultures, identities and discourses. It is possible that staff development courses and their associated educational development discourses, with which many of the staff participants in this study had engaged, were inadequate for preparing staff for the complexity of the conflicting referential frameworks and tensions they experienced within what was espoused and what was practiced within assessment in that domain. The findings of this study indicate that shifting assessment discussions and research to more 'authentic assessment', in terms of foregrounding the relationship of intended and embedded referential frameworks to the academic and professional communities of practice (Belluigi 2015), may improve how staff and students negotiate and problematize what is interpreted by students as 'subjectivity' in FASP assessment.

Having teaching staff engage at a meta-cognitive level about their roles as assessors in addition to the functions and purposes of assessment, in terms of authorship, textuality and readership, may too enable them to better critique their own pedagogical practices from within. For instance, the author's intentionality can operate in relation to the readings of the assessors, towards developing the self-assessment capabilities of students and place some responsibility with them for guiding the readings of their work. Considering this study's indications of students' perceptions of and investment in their actual intentionality, it may be utilised as a significant negotiated assessment indicator for developing and motivating the critical judgment of students. The untapped potential backwash on students' critical engagement during the process of their artmaking and their reflective engagement with the artwork, may enable more purposeful soliciting of feedback and interpretations from diverse sources to "help students to think about the space from which they are thinking, the context in which they are interpreting" (Gooding-Brown, 2000: 48-49). Such negotiations therefore need not be deterministic or teleological, but would enable the student to have more informed agency to make decisions about their work and its reception, which for independent professional practice. This would actively scaffold their development as reflexive practitioners in an uncertain discipline, taking responsibility for their awareness of how the text's meaning and significance may shift through reading in context. Such use of intentionality has the potential of making the students more cognizant and open to the collaborative nature of contemporary notions of authorship and readership. Whether or not these tentative suggestions, to situate the author in interpretation in arts education assessment, would yield the potential I envisage, warrants additional empirical research of interventions in practice.

\section{Conclusion}

Interwoven within art education research is a sense of the value that should be given to metalearning (Clarke and Cripps, 2012; Hargrove, 2012; Nickerson et al., 1985; Winters, 2011) considered central to student creativity and the reflexivity of the artist. However, this analysis of undergraduate curricula revealed a concern for the quality of student engagement at a reflective level, where students evidenced underdeveloped metacognition and critical judgment. Of particular concern, in a discipline as uncertain as fine art visual practice, were the student experiences of alienation from 
aspects of their identity, learning process, and the product of their labour. This study indicates that foregrounding the embedded referential frameworks utilised in assessment practices, and having participants grapple with the complexities of the problem of authorship and its rubbing against interpretation in contemporary art, may significantly improve the ways in which students negotiate the complex judgement processes of assessment, which many in this study constructed as subject. Situating the author in assessment practices may enable more agential criticality as they engage with uncertainty in their practice.

\section{Reference list}

Baldwin J (1962) The creative process. Ridge Press.

Barnett R (2000) University knowledge in an age of supercomplexity. Higher Education 40(4): 409422.

Belluigi DZ (2009) Exploring the discourses around 'creativity' and 'critical thinking' in a South African creative arts curriculum. Studies in Higher Education 34(6): 699-717.

Belluigi DZ (2013) A Proposed Schema for the Conditions of Creativity in Fine Art Studio Practice. International Journal of Education \& the Arts 14(19): 1-22.

Belluigi DZ (2015) The significance of conflicting discourses in a professional degree: assessment in undergraduate fine art practice. Discourse: Studies in the Cultural Politics of Education 38(2); 209-221.

Belluigi DZ (2016) Constructions of Roles in Studio Teaching and Learning. International Journal of Art \& Design Education 35(1): 21-35.

Belluigi DZ (in press) A Framework to Map Approaches to Interpretation. The Journal of Aesthetic Education, forthcoming.

Belluigi DZ and Meistre BA (2012) After Image: Using metaphoric storytelling in the evaluation of a fine art photography course. In: Nygaard C, Courtney N, and Holtham C (eds) Teaching Creativity-Creativity in Teaching (Learning in Higher Education series), Libri Publishing.

Blauvelt A (1998) Remaking theory, rethinking practice. In: Heller S (ed) The education of a graphic designer, New York: Allworth Press, pp. 71-78.

Boler M (1999) Feeling Power: Emotions and Education. London: Routledge.

Bowden J (2004) Capabilities-driven curriculum design. In: Baillie C and Moore I (eds) Effective learning and teaching in engineering, London: RoutledgeFalmer.

Burnard P (2006) Reflecting on the creativity agenda in education. Cambridge Journal of Education.

Burnard P (2007) Prelude: Provocations in Creativity Research. In: Bresler L (ed.) International handbook of research in arts education, Dordrecht: Springer.

Clarke A and Cripps P (2012) Fostering Creativity: A Multiple Intelligences Approach to Designing Learning in Undergraduate Fine Art. International Journal of Art \& Design Education 31(2): 113-26. 
Corner F (2005) Identifying the Core in the subject of Fine Art. International Journal of Art \& Design Education 24(3): 334-342.

Craft A (2006) Fostering creativity with wisdom. Cambridge Journal of Education 36(3): 337-350.

Dallow P (2003) Representing creativeness: practice- based approaches to research in creative arts. Art, Design \& Communication in Higher Education 2(1/2): 49-66.

Danvers J (2003) Towards a Radical 47 Pedagogy: Provisional Notes on Learning and Teaching in Art \& Design. Journal of Art \& Design Education 22(1): 47-52.

Edström A-M (2008) To rest assured: A study of artistic development. International Journal of Education and the Arts 9(3): 1-25.

Freeman J (2006) First Insights : Fostering creativity in university performance. Arts and Humanities in Higher Education 5(1): 91-103.

Friere P (1972) The Pedagogy of the Oppressed. Harmondsworth, Middlesex: Penguin.

Gooding-Brown J (2000) Conversations about Art: A Disruptive Model of Interpretation. Studies in Art Education 42(1): 36-50.

Govier T (2002) Forgiveness and revenge. London ; New York: Routledge.

Habermas J (1972) Knowledge and human interests. In: Craft A, Jeffery B, and Leibling M (eds), Creativity in Education, London: Continuum.

Hargrove R (2012) Fostering creativity in the design studio: A framework towards effective pedagogical practices. Art, Design \& Communication in Higher Education 10(1): 7-31.

Harwood E (2007) Artists in the academy: curriculum and instruction. In: Bresler L (ed.), International handbook of research in arts education. Dordrecht: Springer.

Jackson M (2013) The Squeezed Middle: An Exploration of Creativity, Conformity and Social Class on the Academic Achievement of Undergraduate Students within a UK Art School. International Journal of Art \& Design Education 32(3): 345-351.

Kindler A (2007) Composing in visual arts. In: Bresler L (ed.), International handbook of research in arts education. Dordrecht: Springer, pp. 543-558.

Mann S (2001) Alternative perspectives on the student experience: alienation and engagement. Studies in Higher Education 26(1): 8-19.

Martin P (2002) Challenging the perceptions of adult learners in fine art. Art, Design \& Communication in Higher Education 1(2): 96-107.

McCall C (2016) Art and insecurity. Academia.edu: 1-9.

Nickerson RS, Perkins DN and Smith EE (1985) The teaching of thinking. London: Lawrence Erlbaum.

Pistolesi E (2001) Good art education is good art. Art Education 54(5): 11-17. 
Reid A and Solomonides I (2007) Design students' experience of engagement and creativity. Art, Design \& Communication in Higher Education 6(1): 27-39.

Runco MA (1994) Creativity and its discontents. In: Shaw M and Runco M (eds), Creativity and Affect, Norwood, NJ: Ablex, pp. 102-126.

Schiralli M (2002) Anxiety and Uncertainty in Aesthetic Education. Journal of Aesthetic Education 36(2): 52-66.

Stronach I and MacLure M (1997) Educational Research Undone: The Postmodern Embrace. Philadelphia, Pa: Open University Press.

Usher $\mathrm{R}$ and Johnston $\mathrm{R}$ (1997) Reconfiguring the other. Self and experience in adult education. In: Usher R, Bryant I, and Johnston R (eds), Adult education and the postmodern challenge. Learning beyond the limits, London: Routledge.

Wild L (1998) That Was Then: Corrections and Amplifications. In: Heller S (ed.), The education of a graphic designer, New York: Allworth Press, pp. 39-52.

Winters T (2011) Facilitating Meta-learning in Art and Design Education. International Journal of Art \& Design Education 30(1): 90-101. 